\title{
Análisis socio-ergonómico en la agricultura. Evaluación del sector oleico desde una perspectiva de género y envejecimiento
}

\author{
V. Zorrilla-Muñoz , M.S. Agulló-Tomás y T. García-Sedano \\ Instituto Universitario de Estudios de Género de la Universidad Carlos III de Madrid, Calle Madrid, 126, \\ 28903, Getafe, Madrid
}

\section{Resumen}

Este trabajo es un estudio de los factores de riesgo ergonómico-biomecánicos y, como enfoque principal, adopta un prisma de género y edad. Por ello, se ha utilizado un modelo multimétodo basado en el análisis cuantitativo (cuestionario) y cualitativo (empírico a través de observación de campo). Los resultados muestran la prevalencia de factores de riesgo relacionados con la existencia de una población cada vez más envejecida y feminizada, y con mayor índice de exposición a factores ergonómico-biomecánicos debido al desarrollo de actividades derivadas del uso de herramientas manuales. Del análisis causa-efecto, se ha obtenido una revisión de los trastornos musculoesqueléticos ocupacionales (en adelante TMEO) más frecuentes y que posiblemente puedan llegar a producirse (tendinitis, lumbalgias, dolor muscular, entre otros) por el hecho de desarrollar actividades agrícolas, concretamente en el sector oleico. Como aplicabilidad directa del estudio, se propone el rediseño de las herramientas manuales (en el caso del subsector analizado: el vareador y el uso de tractor), el uso de nuevas herramientas tecnológicas (como los robots colaborativos), así como la realización de actividades orientadas a un envejecimiento saludable como medidas organizativas preventivas de los TMEO.

Palabras clave: género, envejecimiento, agricultura, factores de riesgo ocupacional, ergonomía, evaluación

Socio-ergonomic analysis in agriculture. Evaluation of the oleic sector from a gender and aging perspective

\begin{abstract}
This work is a study of the ergonomic-biomechanical risk factors and, as a main focus, adopts a prism of gender and age. Therefore, a multi-method model based on quantitative (questionnaire) and qualitative (empirical through field observation) analysis has been used. The results indicate the prevalence of risk factors related to the existence of an increasingly aging and feminized population, and with a higher index of exposure to ergonomic-biomechanical factors due to the development of activities derived from the use of manual tools. From the cause-effect analysis, we have obtained a review of workrelated musculoeskeletal disorders (hereafter WRMSD) more frequent and that may possibly occur (tendinitis, low back pain, muscle pain, among others) due to the development of agricultural activities, specifically in the oleic sector. As a direct applicability of the study, the redesign of manual tools is pro-
\end{abstract}

\footnotetext{
* Autor para correspondencia: vzorrill@ing.uc3.es
}

Cita del artículo: Zorrilla-Muñoz V, Agulló-Tomás MS, García-Sedano T (2019). Análisis socio-ergonómico en la agricultura. Evaluación del sector oleico desde una perspectiva de género y envejecimiento. ITEA-Información Técnica Económica Agraria 115(1): 83-104. https://doi.org/10.12706/itea.2019.005 
posed (in the case of the sub-sector analyzed: The olive harvester and the use of tractor), the use of new technological tools (such as collaborative robots), as well as carrying out activities oriented towards healthy aging as preventive organizational measures of WRMSD.

Keywords: Gender, aging, agriculture, occupational risk factors, ergonomics, evaluation.

\section{Introducción}

España es un país envejecido, circunstancia que posee una mayor incidencia en las zonas rurales debido, entre otros factores, a la despoblación de las mismas. Desde el comienzo del éxodo rural en la segunda mitad del siglo $X X$ y hasta los años 80 la población rural se ha visto reducida. Esta circunstancia se perpetúa hasta la fecha, sin la existencia de visos de recuperación. A este respecto, las expectativas son desoladoras.
La Figura 1 muestra el incipiente debilitamiento poblacional, en número de agricultores/as, que viene acaeciendo desde el año 1969. En él cabe destacar la reducción, en más de la mitad, del número absoluto de mujeres activas en el sector agrícola desde dicho año. Sin duda, comparado con la reducción del empleo agrícola masculino, la registrada por las mujeres es mucho menor.

A partir de la década de 1990 se percibe una mayor estabilización del empleo femenino en

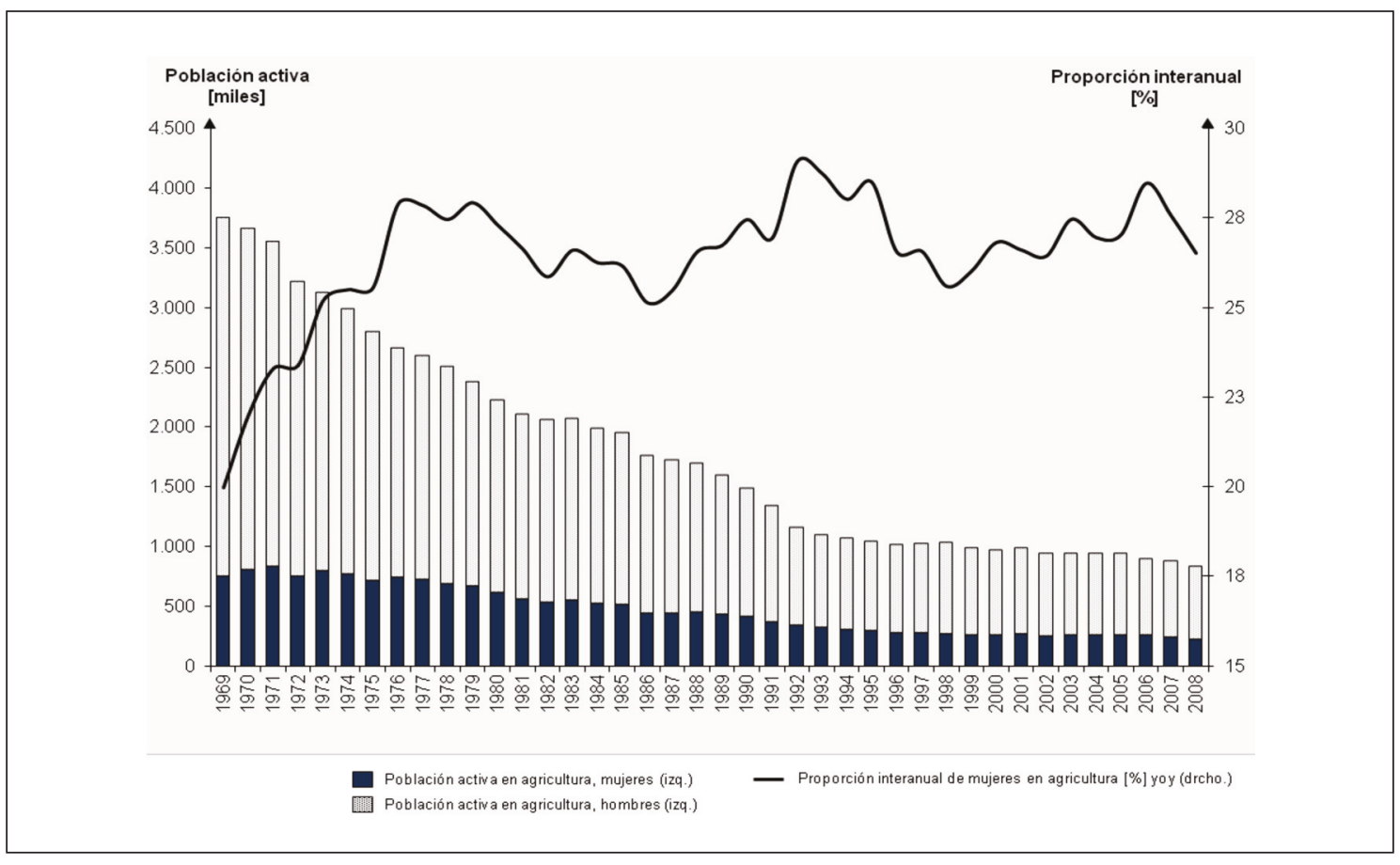

Figura 1. Población activa en el sector agrícola en España, periodo 1969-2008.

Fuente: Zorrilla-Muñoz (2017), basado en datos de ILO (2015).

Figure 1. Working population in the agricultural sector, 1969-2008. 
el sector agrícola, dato que es en gran medida extrapolable al empleo masculino. La actividad agrícola masculina sigue siendo absolutamente mayoritaria también en términos relativos aunque la destrucción de empleo agrícola en términos absolutos -y máxime masculino- ha permitido a las mujeres incrementar su peso relativo en la agricultura. En esta línea conviene recordar que la tasa de envejecimiento en el medio rural es superior a la urbana $(28,3 \%$ en el ámbito rural, $19,5 \%$ en el intermedio y en el urbano el $18 \%)$, siendo además superior en el caso de las mujeres $(32,6 \%$ más mujeres que hombres) (INE, 2017; Abellán García et al., 2018).

La brecha de género y las desigualdades intergénero poseen mayor incidencia y relevancia en la población rural española, incrementándose en el sector poblacional de mayor edad. Tradicionalmente, las mujeres de poblaciones rurales pobres desarrollaron actividades agrícolas como apoyo a la subsistencia de la economía familiar. La feminización del trabajo de campo se ha visto reforzada por los estereotipos vigentes sobre las habilidades de las mujeres.

En la actualidad, es común comprobar como mayoritariamente las mujeres trabajan como "temporeras" estacionales y precisamente, son las mujeres mayores las que están más vinculadas y asumen la realización del trabajo en las explotaciones agrarias como medio para la ayuda familiar (MAPAMA, 2014).

Por otro lado, las mujeres han sido las grandes olvidadas dentro de los procesos atribuidos a roles más masculinos, como el manejo del tractor, desbroce de olivos y otros arbustos, siendo mencionadas de trabajos más estereotipados, como la recolección de frutos, fresas y similares. Para Martínez (2006), entre otros/as autores/as, la mujer ha sido "protagonista del desarrollo económico y social de los siglos XIX y XX", lo que incluye también a las actividades desarrolladas en el campo, poniéndose de manifiesto la importancia de la consideración de un enfoque de género y estudio de diferencias por sexo.

Las políticas europeas en materia de envejecimiento están abordando el debate del retraso/adelanto de la edad de jubilación (SPC, 2007; Bloom et al., 2010; Chai et al., 2011) con dos propósitos, el primero con el objetivo de generar impactos socioeconómicos positivos y contribuir a la reducción de la atención y cuidados en edades tempranas (Batljan y Lagergren, 2005; Börsch-Supan et al., 2005). El segundo, para apoyar, si así lo desea la persona mayor, a construir una experiencia positiva de esta prolongación/adelanto de la edad de trabajo (Agulló-Tomás, 2001), en vías de asegurar un mejor envejecimiento integrando el trabajo/actividad como parte de éste. Sin embargo, se puede concluir que en el sector agrícola la ampliación de la edad laboral a través del retraso de la edad de jubilación, representa en muchos casos una forma obligada de supervivencia, donde las personas quedan expuestas a condiciones de trabajo peligrosas y en situación de riesgo laboral.

La Constitución Española en su artículo 40.2, dentro de los principios rectores de la política social y económica, encomienda a los poderes públicos velar por la seguridad e higiene en el trabajo. Este mandato constitucional supone la obligatoriedad de adoptar una política de tutela de la salud de la población trabajadora a través de la prevención de los riesgos derivados de su trabajo. La Ley 31/1995 de prevención de Riesgos Laborales es su piedra angular y se articula como marco general de las diferentes acciones preventivas, en coherencia con el derecho de la Unión Europea. Así, según el artículo 118 A) del Acta Única Europea, los Estados miembros vienen, desde su entrada en vigor, promoviendo la mejora del medio de trabajo para conseguir el objetivo antes citado de armonización en el progreso de las condiciones de seguridad y salud de los/as trabajadores/as. 
Este propósito se ha ido refrendando a través de distintas directivas que integran el acervo jurídico europeo que pivota sobre la protección de la salud de los/as trabajadores/as en el trabajo, incluidos la población agrícola que está siendo objeto de estudio de este artículo. Ello junto con el Convenio 155, sobre seguridad y salud de los/as trabajadores/as y medio ambiente de trabajo de la Organización Internacional del Trabajo, constituyen el marco básico del ordenamiento jurídico español. Así pues, el mandato constitucional contenido en el artículo 40.2 y la comunidad jurídica establecida por la Unión Europea en esta materia configuran el soporte básico en que se asienta la presente Ley. Junto a ello, los propios compromisos contraídos con la Organización Internacional del Trabajo enriquecen el contenido del texto legal al incorporar sus prescripciones y darles el rango adecuado dentro del sistema jurídico. Junto a este contexto jurídico, conviene destacar que la prevención de riesgos supone la incorporación de una perspectiva ergonómica, ya que cualquier trabajo puede llegar a conducir o conduce al desarrollo de trastornos musculoesqueléticos ocupacionales (TMEO de aquí en adelante) a corto, medio o largo plazo.

La probabilidad ${ }^{1}$ y la incidencia ${ }^{2}$ de dichos trastornos han sido ampliamente estudiadas en diferentes sectores y lugares de trabajo de las sociedades modernas. En general, la etiología de los TMEO puede cotejarse a través de estudios de sección transversal, longitudinal y experimental, que han demostrado que la exposición a una combinación de dos o más riesgos relacionados con el trabajo físico puede causar lesiones o enfermedades musculoesqueléticas (Punnett y Wegman, 2004). En particular, las mayores tasas de aparición de TMEO se han relacionado con el sec- tor agrícola o construcción (Schneider et al., 2010; Almodóvar et al., 2011), más aún, en el caso de las mujeres que trabajan en la agricultura, ya que ellas continúan siendo las grandes invisibles en este sector.

A pesar de la obligatoriedad en España sobre la prevención de riesgos ergonómicos, existen evidencias en recientes estudios sobre el sector agrícola que demuestran la importancia de la aplicación de la ergonomía en el desarrollo de procesos y actividades en el ámbito rural con el fin de mejorar y garantizar una mejora de la calidad de vida -véase a O'Neill y Moore (2016), Vyas y Bajpai (2016), Jain et al. (2016) y Fathallah y Duraj (2017)-.

En la práctica, lo referido se encuentra en fase de implementación y desarrollo. Aún en la actualidad, se observa que las personas que trabajan en la agricultura son más propensas a padecer dolencias ocupacionales musculoesqueléticas que afectan principalmente a la región inferior y superior de la espalda (Chapman y Meyers, 2001; Holmberg et al., 2004; Taechasubamorn et al., 2011; Puntumetakul et al., 2011; Birabi et al., 2012; Liu et al., 2012; Milosavljevic et al., 2012; Osborne et al., 2012; Trask et al., 2014; Keawduangdee et al., 2015).

Este dato es avalado por las cifras registradas en España. Así, las zonas más afectadas son la zona lumbar, seguida del cuello y extremidades superiores e inferiores (Schneider et al., 2010; Almodóvar et al., 2011). Además, el dolor y trastornos se intensifican y/o empeoran a medida que se envejece y se permanece en el mismo puesto de trabajo (Chapman y Meyers, 2001) e incluso los dolores pueden permanecer más allá de la jubilación, sobre todo en las mujeres (Cimas et al., 2017) y se está comprobando que perciben más dolor en general, las mujeres adultas y mayores que sus coetáneos.

1. El porcentaje de una población que se ve afectado con una enfermedad en particular en un momento dado.

2. La tasa de aparición de nuevos casos de una enfermedad particular en una población en estudio. 
Por otra parte, la introducción de automatización de procesos y uso de maquinaria especializada en la agricultura ha supuesto una revolución agrícola en numerosos tipos de cultivos a macro-escala, como son las fresas y los espárragos y, también en la recolección de olivas. Sin embargo, en el cultivo de olivos, todavía prevalece la mano de obra humana frente al uso de equipos más sofisticados.

Para concluir, la accidentabilidad y la siniestrabilidad laboral se ven influenciadas negativamente en el caso de analfabetismo o bajos niveles de estudios (Casale y Fasani, 2013; Puello et al., 2016; Hernández-Trujillo, 2016), donde la problemática se acentúa más aún, y sobre todo en las mujeres.

\section{Objeto y objetivos del estudio}

Este artículo aborda una temática que no suele ser objeto de investigación en la sociología contemporánea: el trabajo agrícola desde una perspectiva de género y envejecimiento de la población. En ese sentido, los estudios centrados en el análisis de actividades agrícolas desde prismas psicosociales y más aún, desde enfoques ergonómicos, han sido y son escasos.

Por ello, este trabajo tiene como objetivo recopilar y analizar datos cuantitativos y cualitativos relacionados con estas actividades.
Así, evalúa los riesgos laborales en la actividad productiva agrícola ${ }^{3} y$, en concreto, se focaliza en el subsector oleico. En particular, se analizan los riesgos biomecánicos-ergonómicos relacionados con los TMEO que afectan a la población adulta y mayor de 54 años en comparación con poblaciones de menor edad, a partir de un enfoque de género, años trabajados en el mismo puesto y nivel de estudios.

Se pretende en el análisis aminorar el problema del enfoque metodológico cuantitativo y para ello se parte de una explotación estadística de bases de datos generales, ya que estos datos (en este caso, atribuidos a un sector global) pueden resultar incompletos, no diferenciándose los subsectores ${ }^{4}$ dependientes directamente de éste.

De esta manera, la investigación realizada se construye sobre el estudio de campo y el análisis cualitativo en el propio puesto de trabajo. Ambos son vitales para el desarrollo ergonómico laboral, el estudio de actividades específicas y la mejora de las interacciones entre las personas y el mundo que las rodea (Wilson, 2000).

En el estudio de campo se evalúan procesos de algunos subsectores agrícolas desde una perspectiva multifactorial ${ }^{5}$. Se ha seleccionado el subsector oleico (y dentro de éste, se ha restringido al puesto de trabajo de "temporera").

3. Diferenciado del trabajo agroindustrial, ya que se ha excluido en esta investigación los procesos de industriales relacionados con la cadena alimentaria (por ejemplo, envasado, limpieza, transporte, entre otras).

4. Se entienden como subsectores del sector agrícola aquellas tareas primarias en agricultura y divididas en procesos que son: tareas del proceso de sembrado, del proceso de recogida, del proceso de regado, entre otras y diferenciadas por tipos de cultivos o cultivos.

5. Sobre la multifactoriedad del proceso de recogida de la aceituna: las personas que trabajan en este subsector realizan tanto actividades propias de actividades agroalimentarias, marcadas por el carácter repetitivo de movimientos y estaticidad corporal y también actividades de naturaleza propia de la agricultura, como el levantamiento, manipulación, arrastre y empuje de cargas. Debido a esto se encuentran expuestos a múltiples factores de riesgo biomecánicos. Además, entre todos los procesos agrícolas, se ha seleccionado el proceso de recogida de la aceituna como muestra, principalmente, porque el trabajo temporal de recogida de aceituna implica tanto a hombres como mujeres, temporal y estacionalmente, coincidiendo con los datos recogidos de MAPAMA (2014). 
Por otro lado, a través del uso multimétodo se da respuesta a las siguientes cuestiones: ¿Cuáles son las conexiones entre un análisis empírico sobre las condiciones de trabajo ergonómicas y la percepción de la salud obtenida a través de cuestionarios? ¿Qué posturas concretas y "constricciones" ergonómicas en la organización del trabajo pueden llegar a provocar lesiones musculoesqueléticas?

\section{Material y métodos}

La metodología adoptada sigue un enfoque preventivo a partir de la identificación de variables tanto sociales como ergonómico-biomecánicas que pueden ayudar a prevenir la aparición de TMEO en poblaciones mayores y más aún, en mujeres.

Se adopta una "triangulación multimétodo", denominada así por la combinación de métodos, técnicas y diferentes enfoques a partir de la obtención de datos cuantitativos que serán posteriormente contrastados con parte de la información obtenida cualitativamente.

Para ello, se han configurado dos métodos de análisis: por una parte y como técnica cuantitativa, explotación de datos de encuestas (en un contexto general de la agricultura) y, por otra, material empírico primario a partir de la observación ergonómica (para las actividades de recogida de la aceituna, características del enfoque multifactorial). La explotación del cuestionario permite estratificar la muestra y comparar los resultados obtenidos para, posteriormente, utilizar el análisis cualitativo a través de la observación directa. Es decir, el análisis estadístico de la encuesta sirve como primera herramienta para decidir si la población estudiada se comporta de manera similar en toda la población desglosada por edad justificando así la decisión de la metodología de evaluación ergonómico-biomecánica que se aplica en el análisis cualitativo.

\section{Muestra del cuestionario}

Este trabajo parte de los datos secundarios obtenidos del Instituto Nacional de Seguridad e Higiene del Trabajo (en adelante INSHT). Desde el año 2007, el Observatorio Estatal de Condiciones del Trabajo (OECT) publica abiertamente encuestas relacionadas con las condiciones laborales. Hasta el momento, ha publicado 5 encuestas, las dos más recientes se engloban además dentro de los estudios europeos. Sin embargo, ninguna de las últimas permite observar una diferenciación de variables ergonómicas-biomecánicas atendiendo a la clasificación del método que las evalúa como recomienda el ITSS (2006) que son: posturas forzadas estáticas; movimientos repetitivos; levantamiento de cargas, Manipulación Manual de Cargas (en adelante MMC) y transporte de cargas; movimientos manuales enérgicos (empuje y arrastre); aplicación de fuerza y esfuerzo físico; y posturas estáticas puras. En consecuencia, se ha optado por los datos definidos en la VII Encuesta Nacional de Condiciones del Trabajo (en adelante ENCT), publicada en el año 2011 (OECT, 2011) para el sector agrícola, que es la última encuesta existente en España que estudia exclusivamente variables ergonómicas-biomecánicas tipificadas según dicha clasificación. Los datos del cuestionario fueron recogidos en el centro de trabajo de los/as entrevistados/as mediante entrevistas personales y siguiendo rutas aleatorias.

Como variables de control cualitativas y como datos descriptivos se han seleccionado y analizado:

- La edad (total, para una $\mathrm{N}=463$, y estratificado para 55 años y más, con una $n=60$ ), ya que la edad correlaciona siempre con el desgaste de la salud (Chapman y Meyers, 2001), con lo que la clave ha sido discriminar y analizar esta última en el puesto de trabajo o tareas específicas analizados. 
Tabla 1. Ficha técnica de estudio.

Table 1. Technical specifications of the survey.

\begin{tabular}{lll}
\hline Características & Estudio cuantitativo & Estudio cualitativo \\
\hline Ámbito de aplicación & Sector agrícola en toda España & $\begin{array}{l}\text { Sector agrícola, proceso de } \\
\text { recogida de aceituna }\end{array}$ \\
Recogida de información & $\begin{array}{l}\text { Cuestionario: VII Encuesta } \\
\text { Nacional de Condiciones } \\
\text { del Trabajo (2011) }\end{array}$ & $\begin{array}{l}\text { Observación directa del proceso } \\
\text { y actividades: recogidas de } \\
\text { imágenes y vídeos }\end{array}$ \\
$\begin{array}{ll}\text { Población dedicada a la } \\
\text { agricultura-ganadería-pesca } \\
\text { en el conjunto del territorio } \\
\text { español }\end{array}$ & $\begin{array}{l}\text { 10 mujeres mayores de } 54 \text { años } \\
\text { dedicadas al proceso de } \\
\text { recogida de aceituna }\end{array}$ \\
$\begin{array}{l}\text { Tamaño de la muestra } \\
\text { calculado (N) }\end{array}$ & $\mathrm{N}=463$ & $\begin{array}{l}\text { Basado en la recogida de vídeos } \\
\text { e imágenes }\end{array}$ \\
$\begin{array}{l}\text { Personas mayores de } \\
\text { 55 años }(\mathrm{n}) \text { del tamaño } \\
\text { de muestra }\end{array}$ & $\mathrm{n}=60$ & $\begin{array}{l}\text { Basado en la recogida de vídeos } \\
\text { e imágenes }\end{array}$ \\
Procedimiento estratificado & $\begin{array}{l}\text { Hombres y mujeres, } \\
\text { clasificados por nivel de estudios, } \\
\text { por edades y por tiempo (años) } \\
\text { de permanencia en el puesto } \\
\text { de trabajo }\end{array}$ & Mujeres mayores \\
\hline
\end{tabular}

Fuente: Elaboración propia, datos presentados en Zorrilla-Muñoz (2017).

- El tiempo de permanencia en el puesto de trabajo, en años, ya que a mayor tiempo desempeñando un mismo trabajo con condiciones ergonómicas no controladas, mayores posibilidades de desarrollo de TMEO (Chapman y Meyers, 2001).

- El nivel de estudios, a fin de analizar la vulnerabilidad de poblaciones de menor grado de estudios (Díaz Méndez, 2011; Casale y Fasani, 2013; Hernández-Trujillo, 2016; Puello et al., 2016) en relación a la exposición a factores biomecánicos.

Los datos de perfil sociodemográfico agrícola de la Tabla 2 muestran que la concen- tración de edad se produce en el grupo de 45-54 años, seguido del grupo del de 55 y más años. Esto demuestra la existencia de una posible población activa futura cada vez más envejecida.

Se aprecia, además, que en el caso del nivel de estudios -en todos los perfiles de edad(ver Tabla 2), la población se concentra en el intervalo o grupo de primarios básicos finalizados. Para las mujeres, el conjunto de la muestra es diferente y variado, lo cual rompe los estereotipos que perfilan la existencia de una mano de obra femenina analfabeta y poco cualificada. 
Tabla 2. Permanencia en el puesto de trabajo actual, edad y nivel de estudios de las personas dedicadas a la agricultura, ganadería y pesca.

Table 2. Continuity in the current work post, age and studies of persons devoted to agriculture, livestock farming and fishing.

\begin{tabular}{|c|c|c|}
\hline Años en el puesto de trabajo actual & \multicolumn{2}{|c|}{ Total [Med. \pm DT] } \\
\hline Total $(\mathrm{N}=463)$ & \multicolumn{2}{|c|}{$9,70 \pm 0,51$} \\
\hline Hombres $(\mathrm{Nh}=316)$ & \multicolumn{2}{|c|}{$10,74 \pm 0,66$} \\
\hline Mujeres $(\mathrm{Nm}=147)$ & \multicolumn{2}{|c|}{$7,44 \pm 0,71$} \\
\hline Total $(n=60)$ & \multicolumn{2}{|c|}{$20,7 \pm 2,66$} \\
\hline Hombres $(\mathrm{nh}=41)$ & \multicolumn{2}{|c|}{$20,68 \pm 2,54$} \\
\hline Mujeres $(n m=19)$ & \multicolumn{2}{|c|}{$20,74 \pm 6,50$} \\
\hline Grupo de edad & Hombres (\%) & Mujeres (\%) \\
\hline $16-24$ & $15(4,75)$ & $2(1,36)$ \\
\hline $25-34$ & $66(20,89)$ & $25(17,01)$ \\
\hline $35-44$ & $98(31,01)$ & $51(34,69)$ \\
\hline $45-54$ & $96(30,38)$ & $50(34,01)$ \\
\hline$=>55^{*}$ & $40(12,66)$ & $18(12,24)$ \\
\hline Totales grupo de edad & $316(100)$ & $147(100)$ \\
\hline Nivel de estudios & Hombres (\%) & Mujeres (\%) \\
\hline No sabe leer ni escribir & $5(1,58)$ & $3(2,04)$ \\
\hline Primarios sin finalizar & $67(21,20)$ & $35(23,81)$ \\
\hline Primarios (EGB, Graduado escolar) & $167(52,85)$ & $80(54,42)$ \\
\hline Formación Profesional primer grado & $26(8,23)$ & $8(5,44)$ \\
\hline Formación Profesional segundo grado & $15(4,75)$ & $8(5,44)$ \\
\hline Bachillerato Superior, BUP, COU y equiv. & $24(7,59)$ & $10(6,80)$ \\
\hline Diplomaturas & $3(0,95)$ & $1(0,68)$ \\
\hline Licenciado Universitario, Arquit. e Ing. & $6(1,90)$ & $2(1,36)$ \\
\hline Otro estudios no reglados & $2(0,63)$ & - \\
\hline Totales nivel de estudios & $315(100)$ & $147(100)$ \\
\hline
\end{tabular}

*Para $\mathrm{N}=462$, existen 2 personas (1 hombre y 1 mujer) que no han respondido a la edad.

Fuente: Elaboración propia y presentado en Zorrilla-Muñoz (2017), datos obtenidos a partir de OECT (2011). 


\section{Metodología de análisis del cuestionario: indicadores y variables}

Las variables de estudio se obtuvieron a partir de la VII ENCT. En total, se seleccionaron 4 indicadores y 8 variables relacionadas, tal y como se muestra en la Tabla 3 que presenta un resumen que relaciona los factores de riesgo ergonómico-biomecánicos que analizan los métodos con las variables objeto de estudio (en el apartado de formulación), indicadores y autores/as que los han utilizado en sus trabajos.
Las variables de control utilizadas son los años que la persona lleva en el puesto de trabajo, el sexo y el nivel de estudios. Tanto el sexo como el nivel de estudios son variables categóricas y, en el caso de sexo dicotómica, donde se ha asociado el valor de 0 para los hombres y 1 para las mujeres. La variable estudios consta a su vez de 6 categorías, siendo el perfil de licenciatura/grado el que se toma como umbral de referencia. Por su parte, la variable relativa a los años que la persona lleva en el puesto de trabajo está medida en años, luego es de tipo continua.

Tabla 3. Variables identificadas en función de los factores de riesgo ergonómicos-biomecánicos. Table 3. Variables identified based on ergonomic and biomechanical risks.

\begin{tabular}{|c|c|c|}
\hline \multicolumn{2}{|c|}{$\begin{array}{l}\text { Factores de riesgo } \\
\text { ergonómico-biomecánicos }\end{array}$} & \multirow{2}{*}{$\begin{array}{l}\text { Formulación de la pregunta en el } \\
\text { cuestionario en relación a factores de } \\
\text { riesgo ergonómico-biomecánicos } \\
\text { (escala de Likert de } 1 \text { a } 5 \text { ) }\end{array}$} \\
\hline Indicador & Referencias & \\
\hline $\begin{array}{l}\text { Aplicación de fuerza física } \\
\text { requerida para el desarrollo } \\
\text { de las tareas y actividades. }\end{array}$ & $\begin{array}{l}\text { (NRC e IOM, 2011; } \\
\text { Zorrilla-Muñoz, } \\
\text { 2012, 2017) }\end{array}$ & E: Aplicar fuerzas importantes. \\
\hline $\begin{array}{l}\text { Posturas de trabajo inadecuadas } \\
\text { (forzada, estáticas o estáticas } \\
\text { puras) que afectan al sistema } \\
\text { musculoesquelético. }\end{array}$ & $\begin{array}{l}\text { (INSHT, 2011; } \\
\text { Zorrilla-Muñoz, } \\
2012,2017)\end{array}$ & $\begin{array}{l}\text { A: Adoptar posturas dolorosas o } \\
\text { fatigantes (de cualquier parte del } \\
\text { cuerpo: espalda, cabeza, manos, etc.). }\end{array}$ \\
\hline $\begin{array}{l}\text { Posturas de trabajo inadecuadas } \\
\text { (forzada, estáticas o estáticas } \\
\text { puras) que afectan al sistema } \\
\text { musculoesquelético. }\end{array}$ & $\begin{array}{l}\text { INSHT, 2011; } \\
\text { (Zorrilla-Muñoz, } \\
\text { 2012, 2017) }\end{array}$ & $\begin{array}{l}\text { B: Estar de pie sin andar. } \\
\text { C: Estar sentado/a sin levantarse. } \\
\text { G: Disponer de muy poco espacio para } \\
\text { trabajar con comodidad. } \\
\text { H: Tener que alcanzar herramientas, } \\
\text { elementos u objetos de trabajo } \\
\text { situados muy altos o muy bajos, o que } \\
\text { obliguen a estirar mucho el brazo. }\end{array}$ \\
\hline Movimientos repetitivos. & $\begin{array}{l}\text { (Armstrong, 1993; } \\
\text { INSHT, 2011; NRC e } \\
\text { IOM, 2011; } \\
\text { Zorrilla-Muñoz, } \\
\text { 2012, 2017) }\end{array}$ & $\begin{array}{l}\text { F: Repetir los mismos movimientos } \\
\text { de manos o brazos. }\end{array}$ \\
\hline $\begin{array}{l}\text { Levantamiento, manipulación } \\
\text { y empuje de cargas. }\end{array}$ & $\begin{array}{l}\text { (INSHT, 2003, 2011; } \\
\text { Zorrilla-Muñoz, } \\
\text { 2012, 2017) }\end{array}$ & D: Levantar o mover cargas pesadas. \\
\hline
\end{tabular}




\section{Muestra del análisis empírico de campo}

Tal y como se ha comentado, los puestos de trabajo observados se corresponden con las actividades que desarrollan las mujeres mayores dentro del proceso de recogida de aceituna, lo cual se viene a denominar como el puesto de trabajo de "temporera". Se partió de un grupo de análisis de 10 operarias procedentes de diferentes empresas del subsector oleico y que lleva más de 10 años realizando este puesto de trabajo. Se realizó un análisis empírico mediante observación ergonómica directa de actividades no mecánicas (donde el uso de maquinaria está muy limitado o se ciñe a la utilización de herramientas de mano) y no estandarizadas (es decir, que la realización de las actividades no está previamente establecida) de tal manera que las actividades son ergonómicamente representativas dentro del sector agrícola (esto es, actividades realizadas en peores condiciones y de manera más rudimentaria). Por lo tanto, la técnica de recogida utilizada es manual.

Por otra parte, las actividades son analizadas a través de la grabación de imágenes y vídeos realizados en el proceso de recogida de aceituna entre enero y febrero del año 2015. En total, se identificaron 30 actividades (ver resultados en Tabla 7).

\section{Metodología de análisis empírico de campo: identificación de actividades y evaluación ergonómica-biomecánica}

En la literatura científica se cita una amplia bibliografía para la evaluación ergonómicabiomecánica. Algunos de estos métodos de evaluación se han recogido en la Tabla 4.

Previa a la selección del método para la evaluación de factores de riesgo se procedió a la identificación de actividades (como se ha mencionado, en total 30). Como técnicas para esta identificación, se ha recurrido a la utilización de diagramas de flujo (Nüllen y Nop- peney, 2007). Posteriormente, se seleccionó la metodología adecuada en función de la actividad observada tal y como queda descrito en la Tabla 4.

Cabe indicar que para la correcta interpretación de las puntuaciones en la evaluación de los métodos, se realizó inicialmente una normalización inter-método según los criterios de puntuación de 1 a 3 (es decir, mediante la transformación a una escala de puntuación de Likert de 3 puntos) y teniendo en cuenta los criterios de puntuación de Everett (1997), donde existen tres posibilidades: el nivel de riesgo es insignificante o no existe (por lo que no se requiere una intervención ergonómica), es moderado (se necesita efectuar modificaciones a medio o largo plazo) y, el nivel de riesgo es elevado (por lo que se requiere una intervención urgente).

Por último y a fin de extraer conclusiones, se llevó a cabo una identificación basada en el análisis causa-efecto de las posibles lesiones que pueden desarrollarse a partir de los factores ergonómicos-biomecánicos.

\section{Resultados y discusión}

A continuación, se muestran los resultados y se discute sobre los mismos, quedando divididos en los dos siguientes apartados: Resultados del cuestionario y; Resultados de la identificación y evaluación ergonómica-biomecánica.

\section{Resultados del cuestionario}

Las Tabla 5 muestra los resultados del análisis estadístico del cuestionario. En primer lugar, se calcula el coeficiente de correlación de Pearson ( $r$ ) para la variable continua correspondiente al tiempo en el puesto de trabajo (medido en años). Se ha encontrado relación entre las variables A (adoptar posturas dolo- 
Tabla 4. Metodología para la evaluación ergonómica-biomecánica (lista no exhaustiva).

Table 4. Methodology for the ergonomic and biomechanichal evalauation (non-exhaustive list).

Factores de riesgo que analizan los métodos

Posturas forzadas y estáticas

Movimientos repetitivos

Levantamiento manual de cargas

Empuje y arrastre de cargas

Aplicación de fuerza y esfuerzo físico

Posturas estáticas puras

Manipulación de cargas y posturas estáticas

Combinación de factores
Métodos de evaluación ergonómica-biomecánica

Rapid Entire Body Assessment "REBA"

Rapid Upper Limb Assessment "RULA"

Ovako Working Analysis System "OWAS"

Postural Loading on the Upper Body Assessment "LUBA"

UNE-EN 1005-4

Pressure Neuropathies Procedure

Armstrong's Method

Posture, Activity, Tools and Handling "PATH"

Swat's Method

Occupational Repetitive Action "OCRA"

Job Strain Index "JSI"

Cubel Model

ISO 11228-3

UNE-EN 1005-5

Assessment of Repetitive Task "ART"

ACGIH TLV "HAL"

The National Institute for Occupational Safety

and Health Method "NIOSH"

Liberty Mutual Insurance Company Tables

UNE-EN 1005-2

ISO 11228-1; ISO 11228-2; ISO 11228-3

Guía del INSHT

REFA

Key Indicator Method "KIM"

Manual Handling Assessment Chart "MAC tool"

Procedimiento de Neuropatías por Presión

Arbouw Guideline

Liberty Mutual Insurance Company Tables

ISO 11228-2

Key Indicator Method "KIM"

Procedimiento de Neuropatías por Presión

Arbouw Guideline

UNE-EN 1005-3

Posture, Activity, Tools and Handling "PATH"

ACGIH TLV "HAL"

Rodgers Muscle Fatigue Analysis "MFA"

ISO 11226

WR Model

Method of Hand Position

Posture Targetting

Rapid Entire Body Assessment "REBA"

Rapid Upper Limb Assessment "RULA"

Postural Loading on the Upper Body Assessment "LUBA"

UNE-EN 1005-4

3D Static Strength Prediction Program (3DSSPP)

Jack Siemens

Fuente: Zorrilla-Muñoz $(2012,2017)$. 


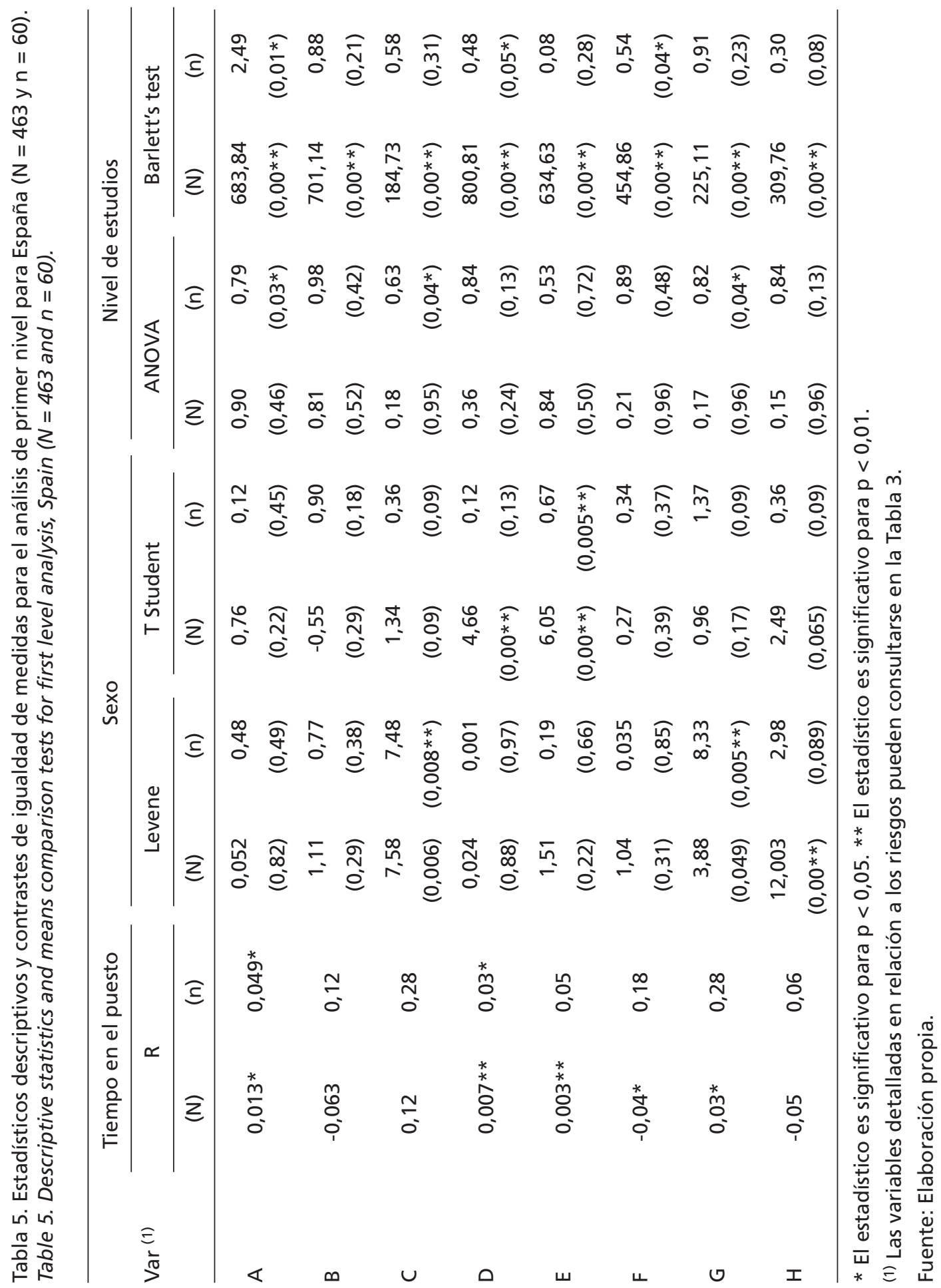


rosas o fatigantes), D (levantar o mover cargas pesadas), E (aplicar fuerzas importantes), $\mathrm{F}$ (repetir los mismos movimientos de manos o brazos) y G (disponer de muy poco espacio), con mayor probabilidad en todos los grupos de edad que en la muestra de mayores de 54 años. En dicha muestra de mayores, cabe destacar los resultados de Pearson en A y D.

En segundo lugar, para las variables dicotómicas se utilizaron pruebas de contraste. Así, se calcula el contraste de varianzas a través del test de Levene y la prueba de t-Student, para el contraste de igualdad de medidas y la variable sexo. En el test de Levene, se obtiene asociación entre las variables $C$ (estar sentado/a sin levantarse) y $\mathrm{G}$ en los grupos de mayores (n) y $\mathrm{H}$ para toda la población (N). Para la prueba de t-Student, los resultados muestran probabilidad de $p<0,01$ en $E$, para el grupo de mayores ( $n$ ) y en toda la población (N). También cabe destacar los valores de $\mathrm{D}$ en toda la población.

En relación al nivel de estudios se aplicó ANOVA para valorar el contraste del conjunto de vector de medidas y el test de Barlett para probar la homocedasticidad. Los resultados muestran probabilidad de $\mathrm{p}<0,05$ para $n$ y $A, C$ y $G$. El test de Barlett devuelve probabilidades de $p<0,01$ en todas las variables para $\mathrm{N}$ y en menor medida para $\mathrm{n}$.

En definitiva, los resultados muestran que en relación al tiempo en el puesto de trabajo, las variables $A$ y $D$ devuelven mejores resultados en la muestra de mayor edad o, lo que es lo mismo, realizar actividades que supongan la adopción de posturas dolorosas/fatigantes y levantar/mover cargas pesadas se intensifican a mayor edad y permanencia en el puesto de trabajo. A es representativa en el caso de la muestra relacionada con un menor nivel de estudios y el grupo de personas mayores.
En cuanto al sexo, es la variable E (aplicar fuerzas importantes) donde se observa más consonancia entre toda la población y en las personas mayores. Por su parte, D, no se observa para el grupo de mayores, lo que indica que en la muestra seleccionada, las mujeres mayores no realizan tanto actividades donde se levante/mueva cargas pesadas como lo hace el grupo global de mujeres.

Cabe destacar que la variable $\mathrm{F}$ (movimientos repetitivos) no es representativa para el grupo de mayores en ninguno de los casos analizados, como tampoco lo es B (estar de pie sin andar) en el grupo de mayores.

En resumen, en el análisis empírico deben considerarse los métodos que apliquen la realización de posturas dolorosas y fatigantes, en primera medida y, posteriormente la aplicación de fuerzas importantes y levantar/mover cargas pesadas ${ }^{6}$.

\section{Resultados de la identificación y evaluación ergonómica-biomecánica}

Como primer paso, se procedió a la identificación por observación directa de las actividades que conforman el proceso de recogida de aceituna mediante el uso de la técnica de diagramas de flujo. La desagregación en diagramas de flujo, representando todas las actividades, permite la identificación de cada una de éstas. De ese modo, se observan cuatro puestos de trabajo diferenciados y sus correspondientes procesos (ver Tabla 6). A su vez, en estos puestos de trabajo se han identificado un total de 30 actividades que finalmente, fueron agrupadas en 4 procesos (grupo A, B, C y D como se muestra en la Tabla 6).

De acuerdo con los datos obtenidos en el análisis de cuestionario y como medida previa a la selección del método de evaluación

6. Entre las limitaciones del cuestionario, cabe destacar que la metodología de la VII Encuesta Nacional de Condiciones del Trabajo no interpreta ni aclara qué se entiende por cargas pesadas o la aplicación de fuerzas importantes. 
Tabla 6. Procesos y actividades identificadas relacionadas en el proceso de recogida de aceituna. Table 6. Processes and activities identified in relation to olives harvesting.

\begin{tabular}{|c|c|c|}
\hline Proceso & Descripción de proceso & Actividades identificadas* \\
\hline $\begin{array}{l}\text { A: preparación } \\
\text { del terreno }\end{array}$ & $\begin{array}{l}\text { Consiste en allanar el terreno } \\
\text { o planchar para facilitar } \\
\text { la recogida del árbol }\end{array}$ & $\begin{array}{l}\text { 1: Subir al tractor; } 2: \text { traslado del tractor a la finca; } \\
\text { 3: preparación del terreno; 4: traslado del tractor } \\
\text { al almacén; 5: bajar del tractor }\end{array}$ \\
\hline $\begin{array}{l}\text { B: recolección } \\
\text { de frutos }\end{array}$ & $\begin{array}{l}\text { Proceso relacionado con la } \\
\text { recolección del fruto que } \\
\text { incluye actividades como } \\
\text { la vibración del árbol, } \\
\text { preparación de fardos, } \\
\text { barrido, entre otras }\end{array}$ & $\begin{array}{l}\text { 1: Subir al tractor; } 2 \text { : traslado del tractor a la finca; } \\
\text { 4: traslado del tractor al almacén; 5: bajar del tractor; } \\
\text { 6: traslado del remolque a la finca; 7: vibración del } \\
\text { olivo mediante vibrador frontal; 8: recogida del } \\
\text { vareador; } 9 \text { : colocación del vareador; } 10 \text { : traslado del } \\
\text { vareador al olivar; } 11: \text { varear el árbol; } 12 \text { : traslado del } \\
\text { vareador a la nave; } 13 \text { : despojamiento del vareador; } \\
\text { 14: traslado del fardo de la finca a la nave; } \\
\text { 15: extensión del fardo; } 16 \text { : recogida del fardo; } \\
\text { 17: traslado del remolque a la nave; } 18: \text { traslado del } \\
\text { cepillo y del recogedor (de finca a nave y viceversa); } \\
\text { 19: barrido de frutos; } 20 \text { : recogida de frutos del } \\
\text { suelo; } 21 \text { : colocación de aceitunas en remolque }\end{array}$ \\
\hline $\begin{array}{l}\text { C: mantenimiento } \\
\text { del olivo }\end{array}$ & $\begin{array}{l}\text { Procesos relacionados con } \\
\text { la poda de los olivos y el } \\
\text { triturado de las ramas } \\
\text { que se podan }\end{array}$ & $\begin{array}{l}\text { 1: Subir al tractor; } 2 \text { : traslado del tractor a la finca; } \\
\text { 4: traslado del tractor al almacén; } 22 \text { : traslado de } \\
\text { tijeras a la finca y almacén; 23: poda de árboles; } \\
\text { 24: triturado de ramas }\end{array}$ \\
\hline $\begin{array}{l}\text { D: preparación } \\
\text { y recogida }\end{array}$ & $\begin{array}{l}\text { Procesos relacionados con } \\
\text { la preparación y recogida, } \\
\text { como son arado del terreno, } \\
\text { estercolado, desbrozado } \\
\text { de la hierba alrededor del } \\
\text { árbol y riego de la finca }\end{array}$ & $\begin{array}{l}\text { 1: Subir al tractor; 2: traslado del tractor a la finca; } \\
\text { 4: traslado del tractor al almacén; } 5 \text { : bajar del } \\
\text { tractor; 25: arado del terreno; } 26: \text { echar estiércol en } \\
\text { el terreno; 27: desbrozar hierba; 28: abonar el campo; } \\
\text { 29: extender goteros; 30: recoger gotero }\end{array}$ \\
\hline
\end{tabular}

* Dependiendo de la actividad, se maneja el tractor para tirar de la herramienta necesaria, por ejemplo, la operación de arado necesita el empuje del tractor.

Fuente: Elaboración propia a partir del estudio de Pedauyé (2015) y datos presentados en Zorrilla-Muñoz (2017).

ergonómica-biomecánica, se conforman dos tipos de variables que son $\mathrm{F}$-relaciona la repetitividad-, y B -relaciona la posición de estar de pie sin andar-.

En el caso de análisis de las actividades de recogida de aceituna, no se ha podido determinar ninguna actividad propiamente repetitiva, posición sentado/a y de pie sin caminar. Sin embargo, se detecta la presencia de factores relevantes como la MMC, la aplicación de esfuerzos o la adopción de posturas doloras y fatigantes. Bajo estas circunstancias, se ha optado por la selección de los métodos REBA y RULA, ya que ambos permiten la evaluación de posturas forzadas y estáticas y otras (aplicación de esfuerzo y levantar/mover cargas pesadas, entre otros), además de su amplia versatilidad y validez. Los resultados son contrastados con el uso de los programas informáticos 3D SSPP y Jack de Sie- 
mens que también permiten la combinación de factores.

Los resultados normalizados del análisis se muestran en la Tabla 7. Se observa que las actividades con mayor nivel de riesgo obtenido a partir del uso de todos los métodos se corresponde con la actividad 9 (colocación del vareador), 11 (varear el árbol), 13 (despojamiento del vareador) y la 15 (extensión del fardo).

Cabe mencionar que la actividad 9, 11 y 13 están expuestas al desarrollo de cualquiera de las lesiones musculoesqueléticas relacionadas con los factores ergonómico-biomecánicos indicados en la Tabla 8 obtenida tras el análisis causa-efecto: posturas forzadas y estáticas, levantamiento, soporte y MMC, movimientos manuales enérgicos, aplicación de fuerza y esfuerzo físico y posturas estáticas puras. Sin embargo, en la 15, se relacionan las posibles lesiones derivadas principalmente de la adopción de posturas forzadas y estáticas, movimientos manuales enérgicos y posturas estáticas puras. Se observa como las principales regiones afectadas se refieren a miembros superiores (Hombro-Brazo y Mano-Muñeca).

Por último, cabe mencionar que el propio método aislado de evaluación ergonómica-biomecánica está sujeto a limitaciones, ya que el propio análisis en este estudio es realizado por una única observadora-experta.

\section{Conclusiones}

Como conclusiones principales, el análisis estadístico a partir de la encuesta a fin de determinar el método de análisis ergonómicobiomecánico ha demostrado la existencia de, como principales factores a destacar, la adopción de posturas forzadas, la aplicación de fuerzas y la manipulación manual de cargas.

Considerando el grupo de mujeres de más de 54 años de edad, se detecta una mayor inci- dencia vinculada con la adopción de posturas forzadas y la aplicación de fuerzas, que además, en el caso del análisis empírico se debe al uso del vareador -tres de las cuatro actividades con riesgo intolerable se deben al uso de esta herramientas de mano-. En este sentido y, si se hubiera considerado el factor repetitividad en ciertas circunstancias de trabajo (por ejemplo, por el hecho de continuar vareando sin programar descansos) aumentaría aún más la intolerabilidad obtenida y, por lo tanto, también aceleraría las posibilidades de desarrollo de TMEO. Además, se ha podido confirmar la ausencia de estudios con enfoque de género también en estas áreas laborales, que se añade a la escasa evaluación e investigación en la relación general entre envejecimiento/género y vejez/feminismo (Agulló-Tomás et al., 2018).

Por otra parte, el análisis causa-efecto a partir de las posibles lesiones muestra que las partes más afectadas se refieren a los miembros superiores, lo cual sugiere que, de alguna forma el uso de herramientas adaptadas a los brazos y manos podría mitigar o reducir el riesgo. Más aún, si se tiene en cuenta que se trata de una población mayor que puede derivar en altas posibilidades de desarrollo de TMEO unido al proceso de envejecimiento (Zorrilla-Muñoz, 2017).

En cuanto a la metodología utilizada en la investigación, cabe mencionar que el trabajo utiliza métodos específicos reconocidos en la bibliografía científica de análisis, válidos en la investigación cualitativa y cuantitativa y que reducen los costes de otros métodos de laboratorio. A pesar de las limitaciones del uso del cuestionario como medio de recolección de datos y la utilización de la observación directa como técnica de evaluación, las ventajas son mayores por lo que se ha realizado el análisis conjuntamente en esta investigación. Los resultados también podrían ser complementados en un futuro a través del uso de otras técnicas cualitativas, como 


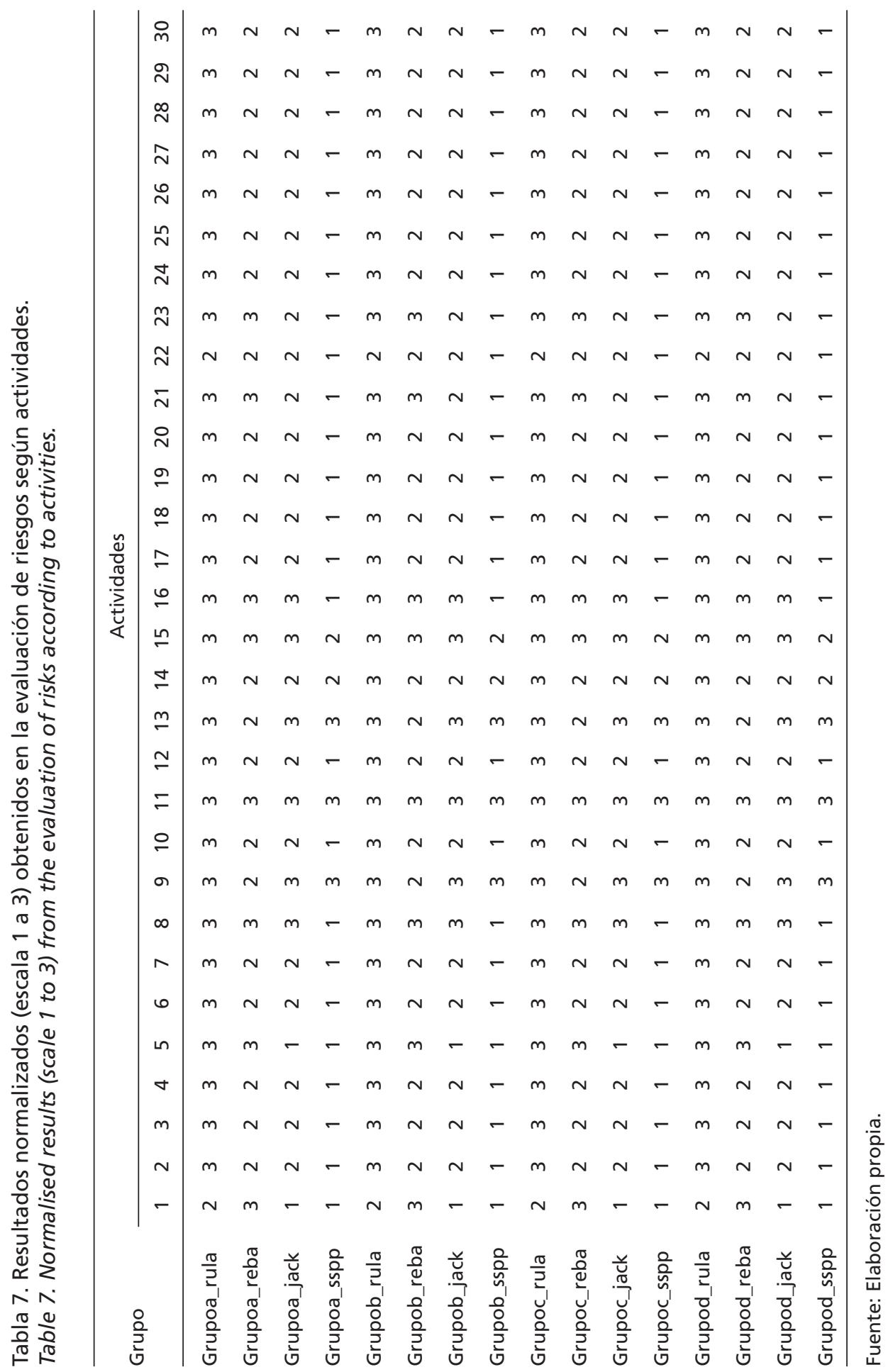




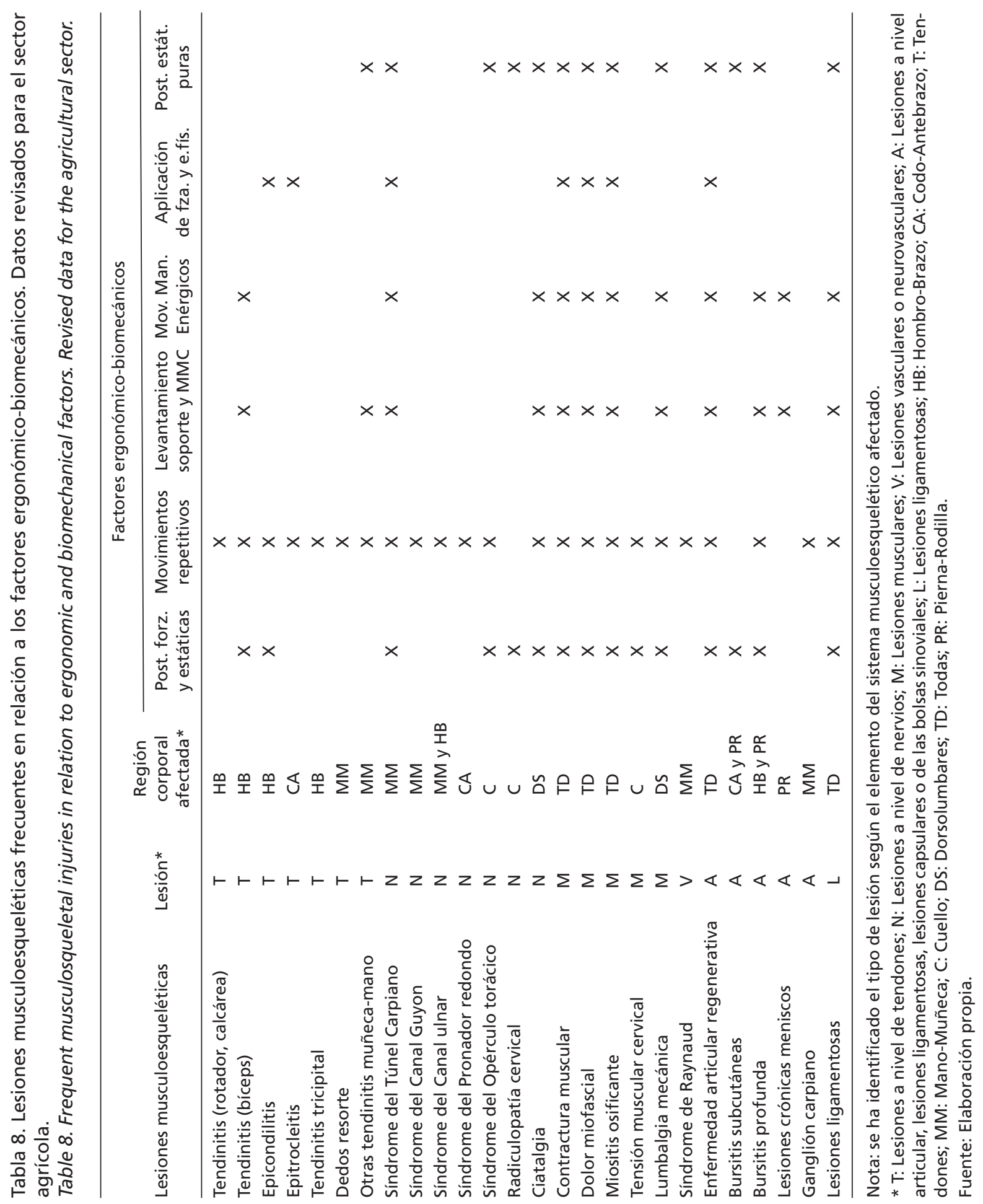


pudiera ser los grupos de discusión o entrevistas en profundidad a mujeres mayores que desarrollen actividades en el subsector oleico. Desde otro enfoque, al igual que se ha realizado en otros estudios ergonómicos [por ejemplo, cabe citar a Douphrate et al. (2017)] el trabajo podría ser aplicado con técnicas de electromiografía para llegar a determinar las demandas bioquímicas de las trabajadoras, lo cual permitiría adaptar diferentes técnicas organizativas en el medio de trabajo.

La variable y constructo de género se ha tenido en cuenta en la evaluación de riesgos, ya que también incide en la posibilidad de existencia de factores biomecánicos durante toda la vida laboral, que pueden llegar a agravarse en la vejez. La mujer mayor rural, foco de este estudio, debería ser evaluada y prevenida de acuerdo a su actividad desempeñada y edad a fin de evitar la aparición de enfermedades y lesiones derivadas del trabajo, como pudieran ser las de tipo musculoesqueléticas aquí tratadas.

Junto a las conclusiones mencionadas, una de las principales propuestas y como fin último de la ergonomía es que el rediseño de la herramienta permita optimizar la interrelación entre las mujeres mayores de 54 años y la tecnología disponible y viable para la elaboración de las actividades. Así, una técnica adecuada podría desarrollarse a fin de evitar el alargamiento de brazos, por ejemplo, a través de la colocación de un artefacto sobre una base estable y procurando el movimiento autónomo del equipo durante el vareamiento. En relación a la actividad del extensión de fardo, se ha detectado la aplicación de movimientos enérgicos y manipulación de cargas, con lo que esta actividad podría ser rediseñada evitando el movimiento manual de fardos y utilizando maquinaria para tal efecto (por ejemplo, a través del tractor/cosechadora a la cual se le podría adaptar un artilugio para la recolocación y extensión de dichos fardos).

Evidentemente, la automatización de procesos agrícolas y el uso de tractores y maquina- ria especializada, evitaría cualquier tipo de riesgo ergonómico. Sin embargo, lejos de ser una solución actual viable en todos los tipos de cultivos de olivos, la mano de obra, hoy por hoy, continúa siendo la principal forma de recolección de la aceituna. Además, el uso de maquinaria motorizada con combustibles fósiles, aumenta las emisiones y contaminación del aire, por lo que no sería una propuesta adecuada medioambientalmente dentro del actual marco de la "Política Agrícola Común" en la Unión Europea, ya que éste instrumento gestiona, entre otras, las subvenciones sobre las prácticas agrícolas sostenibles. Dentro de un contexto innovador, la introducción de Cobots (Collaborative Robots) podría ayudar a la realización de actividades relacionadas con los brazos, evitando el uso desmedido de los mismos.

Siguiendo esta misma línea y desde otra perspectiva, el uso de nanomateriales y la nanotecnología en aplicaciones ergonómicas supone un desafío aún sin explorar (Kim, 2016). Así, por ejemplo, la utilización de equipos de protección personal (guantes y trajes) a través de nanomateriales que soporten alta presión (como los fullerenos, entre otros) podría ayudar a mejorar la absorción de impactos en el sistema musculoesquelético derivados de la realización de movimientos enérgicos, posturas forzadas o levantamiento manual de cargas.

Tampoco debe olvidarse que las anteriores medidas preventivas ergonómico-biomecánicas podrían ir acompañadas de propuestas centradas en acciones encaminadas al estilo de vida dentro y fuera de la organización tal y como menciona Zorrilla-Muñoz (2013): el uso de técnicas de higiene postural, kinesiología y el uso de terapias complementarias -como puede ser el masaje tonificante- así como la práctica habitual de ejercicio físico potenciando la fuerza, resistencia y la coordinación muscular, la realización de ejercicios de estiramientos de grupos musculares, para conseguir disminuir la prevalencia y la inci- 
dencia de la patología o la práctica de ejercicio físico intercalada durante el trabajo.

Otra medida preventiva, sin lugar a dudas, debe ir orientada a la formación e información de las trabajadoras a fin de evitar y mitigar prácticas de riesgo. Una formación más efectiva en el envejecimiento debería partir de tácticas intergeneracionales. Desde este ámbito, el mentoring inverso, donde el/la experto/a es la persona joven, puede suponer un enriquecimiento de las personas mayores y fomentar el aprendizaje de medidas preventivas.

Más allá de los factores de tipo ergonómicobiomecánico, conviene enfatizar la multifactoriedad del desarrollo de los TMEO, por lo que deberían evaluarse y estudiarse en la medida que sea posible, factores de tipo psicosociales, organizativos, genéticos, individuales y ambientales, entre otros (ZorrillaMuñoz et al. 2013; Zorrilla-Muñoz, 2013).

Sin lugar a dudas, los riesgos específicos vinculados al género y relacionados con la discriminación en el acceso a determinadas categorías, la brecha salarial, el acoso, entre otros, inciden en la salud psíquica/mental y psicosocial de las trabajadoras. Para acotar y eliminar estas situaciones, de conformidad con la Ley de Igualdad, son precisas las medidas de vigilancia y sanción y sobre todo desde el enfoque de la educación inclusiva. Así, en el contexto al que se refiere este artículo se ha detectado que apenas existen políticas o planes de igualdad (o en su defecto, protocolos, procedimientos y/o programas desde la responsabilidad social corporativa) que aborden estas cuestiones y ello supone, sin duda, un desafío.

Desde otro prisma, el presente estudio explicita el reto que en materia de prevención de riesgos laborales implica la prolongación de la edad de jubilación en el sector agrícola. Postponer la jubilación puede suponer la continuación de condiciones inadecuadas de trabajo (Agulló-Tomás, 2001) que perpetúan la permanencia de factores de riesgo ergonómicos-biomecánicos y la posibilidad de desarrollo de TMEO debido a todo ello. En ese sentido, esto se agrava cuantos más años se permanezca en el mismo puesto de trabajo y empeora, como en otras actividades, en el caso de las mujeres con un menor nivel de estudios. De nuevo y al igual que sucede en otras investigaciones que se enfocan en el género y el envejecimiento, se constata la necesidad de seguir evaluando e investigando en profundidad y a través del multimétodo.

\section{Agradecimientos}

Las autoras desean agradecer el apoyo a las/os integrantes del Programa ENCAGE-CM (http://encage-cm.es/) (Ref. S2015/HUM-3367, 2016-2019) destinado a actividades I+D sobre Envejecimiento Activo, Calidad de Vida y Género, financiado por la Comunidad de Madrid, Consejería de Educación, Juventud y Deporte, Programas de Actividades de I + D entre grupos de Investigación de la Comunidad de Madrid en Ciencias Sociales y Humanidades, cofinanciado con Fondo Social Europeo. Igualmente, nuestro agradecimiento a las/os miembros del Instituto Universitario de Estudios de Género de la Universidad Carlos III de Madrid (http://uc3m.es/estudiosdegenero). Por último, queremos agradecer el apoyo y colaboración de Marc Petz, Ph.D. y María Pedauyé Rueda.

Parte de este artículo fue defendido en la tesis doctoral "Investigación sobre las personas mayores desde la vivienda, agricultura, emisiones y cuidados. Aplicación de una perspectiva sociológica, preventiva y de género". También ha sido presentado en forma de póster en el XII Congreso Español de Sociología. Grandes transformaciones sociales, nuevos desafíos para la Sociología (2016), organizado por la Federación Española de Sociología (programa con ISBN 978-84-6086210-9). 


\section{Referencias bibliográficas}

Abellán García A, Ayala García A, Pérez Díaz J, Pujol Rodríguez R (2018). Un perfil de las personas mayores en España. Indicadores estadísticos básicos. Informes Envejecimiento en red 17. 34 pp. Disponible en: http://envejecimiento.csic.es/ documentos/documentos/enred-indicadoresbasicos18.pdf (Consultado: 28 noviembre 2018).

Agulló-Tomás MS (2001) Mayores, actividad y trabajo en el proceso de envejecimiento y jubilación: Una aproximación psico-sociológica. Ed. IMSERSO, Madrid, España. 858 pp. Edicion online 2012. Disponible en: http://imserso.es/imserso_01/documentacion/publicaciones/colecciones/colecciones_extinguir/otras_publicacione s/IM_050821 (Consultado: 1 febrero 2018).

Agulló-Tomás MS, Zorrilla-Muñoz V, Gómez MV (2018). Género y evaluación de programas de apoyo para cuidadoras/es de mayores. Prisma Social: revista de investigación social 21: 391415. Disponible en: http://revistaprismasocial.es/article/view/2469 (Consultado: 2 diciembre 2018).

Almodóvar A, Galiana ML, Hervás P, Pinilla FJ (2011). VII Encuesta Nacional de Condiciones de Trabajo del Instituto Nacional de Seguridad e Higiene en el Trabajo. Disponible en: http:// www.insht.es/InshtWeb/Contenidos/Documentacion/FICHAS\%20DE\%20PUBLICACIONES/EN\% 20CATALOGO/OBSERVATORIO/Informe \%20(VII \%20ENCT).pdf (Consultado: 10 enero 2018).

Armstrong T. (1993) A conceptual model for workrelated neck and upper-limb musculoskeletal disorders. Scandinavian Journal Work and Environmental Health. 19: 73-84. https://doi.org/ 10.5271/sjweh.1494

Batljan I, Lagergren M (2005). Future demand for formal long-term care in Sweden. European Journal of Ageing 2(3): 216-224. DOI: 10.1007/s10433005-0002-0

Birabi BN, Dienye P, Ndukwu G (2012). Prevalence of low back pain among peasant farmers in a rural community in South South Nigeria. Rural and remote health 12:1920. Disponible en: https://www.rrh.org.au/journal/article/1920 (Consultado: 2 enero 2018).
Bloom DE, Canning D, Fink G (2010). Implications of population ageing for economic growth. Oxford Review of Economic Policy 26(4): 583612. https://doi.org/10.1093/oxrep/grq038

Börsch-Supan A, Hank K, Jürges H (2005). A new comprehensive and international view on ageing: introducing the 'Survey of Health, Ageing and Retirement in Europe'. European Journal of Ageing 2(4): 245-253. https://doi.org/ 10.1007/s10433-005-0014-9

Casale G, Fasani M (2013). Nuevos desafíos para la administración e inspección del trabajo en el contexto de la reciente crisis económica. Revista Latinoamericana de Derecho Social 17: 179-195. https://doi.org/10.1016/S1870-4670(13)71978-X

Chai J, Horneff W, Maurer R, Mitchell OS (2011). Optimal portfolio choice over the life cycle with flexible work, endogenous retirement, and lifetime payouts. Review of Finance 15(4): 875907. https://doi.org/10.1093/rof/rfr016

Chapman L, Meyers J (2001). Ergonomics and musculoskeletal injuries in agriculture: recognizing and preventing the industry's most widespread health and safety problem. Disponible en: https:// www.cdc.gov/niosh/nioshtic-2/20022184.html (Consultado: 12 diciembre 2017).

Cimas M, Ayala A, Sanz B, Agulló-Tomás MS, Escobar A, Forjaz MJ (2017). Chronic musculoskeletal pain in European older adults: Cross national and gender differences. European Journal of Pain 22(2): 333-345. https://doi.org/10.1002/ ejp. 1123

Díaz Méndez C (2011). Perfiles de mujeres jóvenes rurales de baja cualificación. Un estudio de caso para la comprensión de sus estrategias de inserción sociolaboral en Asturias (España). Revista internacional de Sociología 69(3): 725744. https://doi.org/10.3989/ris.2009.07.16

Douphrate DI, Fethke NB, Nonnenmann MW, Rodriguez A, Hagevoort R, Gimeno Ruiz de Porras D (2017). Full-shift and task-specific upper extremity muscle activity among US large-herd dairy parlour workers. Ergonomics 60(8): 10421054. https://doi.org/10.1080/00140139.2016. 1262464 
Everett J (1997). Ergonomic analysis of construction tasks for risk factors for overexertion injuries NIOSH Grant 5 R03 OH03154-02, Technical Report UMCEE 96-27. Department of Civil \& Environmental Engineering, University of Michigan. Ann Arbor, EEUU.

Fathallah F, Duraj V (2017). Small changes make big differences: the role of ergonomics in agriculture. Resource Magazine 24(6): 12-13.

Hernández-Trujillo JM (2016). Cortadores de café en México. El inframundo del trabajo decente. Ra Ximhai 12(4): 93-110.

Holmberg S, Thelin A, Stiernström E-L, Svärdsudd $K$ (2004). Psychosocial factors and low back pain, consultations, and sick leave among farmers and rural referents: a population-based study. Journal of Occupational and Environmental Medicine 46(9): 993-998. https://doi.org/10.1097 /01.jom.0000137715.33662.02

ILO (2015). Statistics and Database. International Labour Organization. Disponible en: https:// www.ilo.org/global/statistics-and-databases/ lang-en/index.htm (Consultado: 10 marzo 2018).

INE (2017). España en cifras. Instituto Nacional de Estadística. Disponible en: http://www.ine.es/ prodyser/espa_cifras/2017/index.html. (Consultado: 3 marzo 2018).

INSHT (2003). Guía Técnica para la evaluación y prevención de los riesgos relativos a la Manipulación manual de cargas. Instituto Nacional de Seguridad e Higiene en el Trabajo, Madrid, España. 60 pp. Disponible en: http://www.insht. es/InshtWeb/Contenidos/Normativa/GuiasTecnicas/Ficheros/cargas.pdf (Consultado: 2 diciembre 2017).

INSHT (2011). Portal de los trastornos musculoesqueléticos. Disponible en: http://www.insht.es/ portal/site/MusculoEsqueleticos/. (Consultado: 2 diciembre 2017).

ITSS (2006). 7. Factores ergonómicos y psicosociales. 7.2 Guía de Actuación Inspectora en Factores Ergonómicos. Inspección de Trabajo y Seguridad Social, Madrid, España. 12 pp. Disponible en: http://www.mitramiss.gob.es/itss/ITSS/ITSS_ Descargas/Atencion_ciudadano/Normativa_documentacion/Riesgos_laboral/7.2_GUIA_Factores_Ergonomicos.pdf (Consultado: 1 julio 2018).
Jain R, Meena M, Dangayach GS (2016). Need of agriculture hand tool design using quality and ergonomics principles. En: CAD/CAM, Robotics and Factories of the Future. Lecture Notes in Mechanical Engineering. (Eds. Mandal DK, Syan CS), pp. 77-84. Springer. https://doi.org/10.1007/ 978-81-322-2740-3_9

Keawduangdee $P$, Puntumetakul R, Swangnetr M, Laohasiriwong W, Settheetham D, Yamauchi J, Boucaut R (2015). Prevalence of low back pain and associated factors among farmers during the rice transplanting process. Journal of Physical Therapy Science 27(7): 2239-2245. https:// doi.org/10.1589/jpts.27.2239

Kim IJ (2016) Ergonomic challenges for nanotechnology safety and health practices. Journal of Ergonomics 6(5): e160. https://doi.org/10. 4172/2165-7556.1000e 160

Liu X, Wang L, Stallones L, Wheeler KK, Zhao W, Smith GA, Xiang H (2012). Back pain among farmers in a northern area of China. Spine 37(6): 508-514. https://doi.org/10.1097/BRS.0b0 $13 \mathrm{e} 318221 \mathrm{e} 83 \mathrm{f}$

MAPAMA (2014). Medio Rural: trabajando en femenino. Ed. Ministerio de Agricultura, Alimentación y Medio Ambiente. Disponible en: https://www.mapa.gob.es/es/desarrollo-rural/temas/igualdad_genero_y_des_sostenible/MR\%2 Otrabajando\%20en\%20femenino_digital_tcm3 0-131214.pdf. (Consultado: 14 noviembre 2017).

Milosavljevic S, Bagheri N, Vasiljev RM, Mcbride DI, Rehn B (2012). Does daily exposure to whole-body vibration and mechanical shock relate to the prevalence of low back and neck pain in a rural workforce? The Annals of Occupational Hygiene 56(1): 10-17. DOI: 10.1093/annhyg/mer068

NR, IOM (2011). Musculoskeletal disorders and the workplace: Low back and upper extremities. Panel on Musculosketal Disorders and the workplace. Commission on Behavioral and Social Sciences and education. National Research Council and Institute Of Medicine.

Nüllen H, Noppeney T (2007). Lehrbuch qualitätsmanagement in der arztpraxis: entwicklung und einführung eines QMS. Deutscher ÄrzteVerlag. 217 pp.

O'Neill D, Moore D (2016). Human factors and ergonomics practice in agriculture: The Challen- 
ges of Variety and Complexity. En: Human Factors and Ergonomics in Practice: Improving System Performance and Human Well-Being in the Real World (Ed. Shorrock S, Williams C), pp. 331-350. CRC Press.

OECT (2011) VII Encuesta de Condiciones del Trabajo (ENCT). Observatorio Estatal de Condiciones de Trabajo. Disponible en: http://encuestasnacionales.oect.es/ (Consultado: 1 marzo 2018).

Osborne A, Blake C, Fullen BM, Meredith D, PheIan J, McNamara J, Cunningham C (2012). Prevalence of musculoskeletal disorders among farmers: A systematic review. American Journal of Industrial Medicine 55(2): 143-158. https:// doi.org/10.1002/ajim.21033

Pedauyé M (2015). Análisis ergonómico de tipo biomecánico en puestos de trabajo del sector agrícola. Trabajo Fin de Grado. Disponible en: https://www.uc3m.es/biblioteca/inicio (Consultado: 14 julio 2018).

Puello EC, Amador CE, Luna JM (2016). Determinantes sociales de salud en los agricultores del resguardo indígena Zenú. Revista Salud UIS 48(1): 14-26 DOI: 10.18273/revsal.v48n1-2016002

Punnett L, Wegman DH (2004). Work-related musculoskeletal disorders: the epidemiologic evidence and the debate. Journal of electromyography and kinesiology 14(1): 13-23. https://doi. org/10.1016/j.jelekin.2003.09.015

Puntumetakul R, Siritaratiwat W, Boonprakob Y, Eungpinichpong W, Puntumetakul M (2011). Prevalence of musculoskeletal disorders in farmers: Case study in Sila, Muang Khon Kaen, Khon Kaen province. Journal of Medical Technology and Physical Therapy 23(3): 297-303.

Schneider E, Irastorza X, Copsey S (2010). OSH in figures: Work-related musculoskeletal disorders in the EU - Facts and figures. European Agency for Safety and Health at Work, Luxemburgo. https://doi.org/10.2802/10952

SPC (2007). Promoting longer working lives through pension reforms. First Part: Flexibility in retirement age provision. Social Protection Committee, European Union, Brussels.

Taechasubamorn P, Nopkesorn T, Pannarunothai S (2011). Prevalence of low back pain among rice farmers in a rural community in Thailand. The Journal of the Medical Association of Thailand 94(5): 616-621.
Trask C, Mathiassen SE, Wahlström J, Forsman, M (2014). Cost-efficient assessment of biomechanical exposure in occupational groups, exemplified by posture observation and inclinometry. Scandinavian Journal of Work, Environment \& Health 40(3): 252-265. https://doi.org/10.5271/ sjweh.3416

Vyas R, Bajpai N (2016). Ergonomics in agriculture: An approach to quality life of farm communities. Current Advances in Agricultural Sciences (An International Journal) 8(1): 92-95. https:// doi.org/10.5958/2394-4471.2016.00019.8

Wilson JR (2000). Fundamentals of ergonomics in theory and practice. Applied Ergonomics 31(6): 557-567. https://doi.org/10.1016/50003-6870(00) 00034-X

Zorrilla-Muñoz V (2012). Trastornos musculoesqueléticos de origen laboral en actividades mecánicas del sector de la construcción. Investigación mediante técnicas de observación directa, epidemiológicas y software de análisis biomecánico. Tesis doctoral. Disponible en: http://dehesa.unex.es/handle/10662/85/browse? value $=$ Zorrilla+Mu\%C3\%B1oz\%2C+Vanesa\&ty pe=author (Consultado: 18 noviembre 2018).

Zorrilla-Muñoz V, Montero I, Lorente R, Miranda MT (2013). Enfoque epidemiológico sobre los factores de riesgo biomecánico por instalaciones mecánicas en edificios. Ciencia \& Trabajo 15(46): 24-30. https://doi.org/10.4067/S0718-244 92013000100006

Zorrilla-Muñoz V (2013). Estrategias eficaces y definitivas para la prevención, reducción y eliminación de los trastornos musculoesqueléticos en el sector de la construcción. ERGA Noticias 130: 15-17. Disponible en: http://www.insht.es/ InshtWeb/Contenidos/Documentacion/PUBLICACIONES\%20PERIODICAS/ErgaNoticias/Ficheros/2013/erganoticias130.pdf.

Zorrilla-Muñoz V. (2017). Investigación sobre las personas mayores desde la vivienda, agricultura, emisiones y cuidados. Aplicación de una perspectiva sociológica, preventiva y de género. Tesis doctoral. Disponible en: https://e-archivo.uc3m.es/ handle/ 10016/25505 (Consultado: 18 noviembre 2018).

(Aceptado para publicación el 18 de febrero de 2019) 